\title{
Gênero no consultório médico: as contribuições da fala-em-interação para a humanização da atenção à saúde da mulher
}

\author{
Humanização, gênero, poder: \\ contribuições dos estudos de fala- \\ em-interação para a atenção em \\ saúde.
}
OSTERMANN, Ana C.; MENEGHEL, Stela N. (Orgs.).

Rio de Janeiro: Editora Fiocruz; São Paulo: Mercado de Letras, 2012. 167p.

A coletânea Humanização, gênero, poder: contribuições dos estudos de fala-em-interação para a atenção em saúde consiste em uma reunião de estudos que se debruçam sobre as interações que se dão no contexto do cuidado à saúde. Todos os estudos têm por base interações gravadas, integralmente transcritas e posteriormente analisadas através dos pressupostos da Análise da Conversa. ${ }^{1}$ Hão de se beneficiar do livro estudantes e profissionais, não apenas das ciências da saúde, mas também os interessados em estudos de linguagem e gênero, pois o livro traz uma análise substancial de como operam na interação questões como gênero, heteronormatividade e a abordagem de temas, interacionalmente delicados, relacionados, como desejo sexual, impotência e o exercício da sexualidade de mulheres fora do casamento.

No capítulo inaugural, as organizadoras, a linguista Ana Cristina Ostermann e a médica Stela Nazareth Meneghel, apontam para o fato de que o crescente número de estudos que se debruçam sobre questões linguístico-interacionais em contextos de saúde demonstram que há a busca de uma formação mais interdisciplinar e integra dos profissionais de saúde. De acordo com as autoras, o eixo de atenção tem se deslocado do foco no conhecimento técnico-científico, de forma a incorporar também a importância da comunicação entre o profissional de saúde e o paciente, buscando, desse modo, efetivar a integralidade e a humanização dos atendimentos médicos. Contudo, conforme as autoras pon- tuam, pesquisas nacionais dedicadas à fala-eminteração em contextos de atendimentos à saúde ainda são escassas. Essa coletânea, por ser a primeira a se debruçar sobre estudos de interações gravadas de atendimentos à saúde, tornase uma ferramenta valiosa para se compreender melhor o papel da linguagem na busca pela humanização da saúde, especialmente no que tange a atendimentos a pacientes mulheres.

Essa coleção está organizada em cinco partes temáticas. A Parte I, além do capítulo introdutório apresentado anteriormente, se constitui de um capítulo metodológico, no qual Ana Cristina Ostermann detalha a perspectiva teóricometodológica da Análise da Conversa (AC), suas origens e suas relações com outras áreas do conhecimento. Nesse capítulo, Ostermann destaca que o objetivo primordial da AC não é analisar o conteúdo da fala, mas o modo como os falantes realizam, através da linguagem, suas ações no dia a dia. Sendo a fala uma atividade organizadora central em atendimentos médicos, seu estudo oferece contribuições bastante concretas para qualificar esses atendimentos.

Na Parte II, denominada "Momentos delicados e relações de poder", iniciam-se os estudos provenientes de análises propriamente ditas. No capítulo intitulado "Assuntos tabus e momentos delicados em consultas ginecológicas e obstétricas", Ana Ostermann e Débora Rosa analisam momentos delicados que podem ser evidenciados através de fenômenos como hesitações, pausas, atrasos na produção de fala e evitação de alguns termos e/ou assuntos que se revelam como tabus.

Na fala das pacientes, foi observado que, ao nomear determinadas partes de seu corpo, é recorrente a substituição do termo formal por outro (por exemplo, a substituição da palavra vagina por perereca), assim como a total omissão do termo em questão, o que aponta para a delicadeza desse momento interacional. Quando assuntos relacionados à sexualidade foram abordados, as pacientes se referem a eles de forma vaga e metafórica, o que pode por vezes gerar problemas de compreensão. O estudo evidencia que abandonar determinados tópicos em curso ou omitir descrições pertinentes à saúde 
da mulher podem gerar consequências para os atendimentos, pois as pacientes podem não ser plenamente atendidas em suas necessidades.

O despreparo dos médicos participantes desse estudo para lidar com momentos de delicadeza também se revela quando uma das pacientes ri ao falar sobre desejo sexual e, em retorno, ouve uma reprimenda do médico, que não demonstra qualquer entendimento daquele riso como um sinal de desconforto. As autoras acreditam que os médicos, com vistas a minimizar possíveis danos e/ou constrangimento às pacientes, podem colaborar produzindo o termo problemático, ou coconstruindo o tópico que se revela delicado para elas.

Contudo, o que mais chama a atenção nesse estudo é a assunção, por parte dos médi$\cos$, de que ter uma vida sexual ativa depende de ter uma relação matrimonial. Isso se revela quando a possibilidade de procedimento para esterilização é discutida, momento no qual médicos questionam a ausência de um marido quando uma mulher deseja realizar uma ligadura e se declara solteira.

Ainda na Parte II, o capítulo "As relações de poder nas consultas ginecológicas e obstétricas", de Ana Ostermann e Renata Ruy, trata do exercício de poder que se constitui na e pela falaem-interação. Nesse capítulo, a sequência Iniciação - Resposta - Avaliação (IRA) é analisada de modo inaugural em estudos de fala-em-interação em atendimentos médicos, já que consiste em uma estrutura comumente encontrada e estudada em ambientes de sala de aula tradicional. Trata-se de uma sequência altamente assimétrica, pois apenas um dos interlocutores pergunta e avalia a resposta proferida pelo/s outro/ s. As análises apontam a relação assimétrica entre médicos e pacientes no estudo. As autores afirmam que não há nenhuma ocorrência de resistência às perguntas dos médicos, o que evidencia que o exercício de poder, no que se refere ao direito de iniciar sequências IRA, estó restrito apenas aos profissionais de saúde. No entanto, não se pode deixar de ressaltar a complexidade que essa estrutura demonstra na relação médico-paciente, pois pode servir a fins distintos, humanizadores ou não. Há profissionais que fazem uso dessa estrutura a fim de aferir o conhecimento que a paciente tem para, só então, proceder com explicações acerca daquilo que as pacientes ainda não sabem

A terceira parte da coletânea, "Estratégias de Humanização", é inaugurada pelo capítulo de Ana Ostermann e Joseane Souza, intitulado "As explicações feitas pelas pacientes para as causas de seus problemas de saúde: como os médicos lidam com isso". O capítulo analisa o fenômeno interacional denominado atribuição, que consiste em explicações voluntárias realizadas por pacientes sobre causas para seus problemas de saúde.

A literatura aponta casos em que os médicos não lidam com as atribuições feitas pelas pacientes, entretanto, o mesmo não ocorre nos dados analisados por Ostermann e Souza. Embora as pacientes expressem seus saberes sobre sua saúde de formas bastante complexas, os médicos não deixaram de se orientar para todas as atribuições e fornecer respostas a elas, mesmo quando apresentadas de forma sutil e indireta. Isso indica que os profissionais de saúde participantes desse estudo estão atentos em ouvir e validar o conhecimento trazido pela paciente para a consulta médica. As contribuições desse trabalho, portanto, proporcionam insumos para a compreensão de como a humanização em saúde pode ocorrer de forma concreta, através da comunicação.

Em "A formulação explicitando a compreensão mútua entre médico e paciente: uma forma de humanizar os atendimentos", Ana Ostermann e Caroline Silva tratam do fenômeno interacional denominado "formulação", que consiste em uma explicitação da compreensão do que está acontecendo no aqui-e-agora da interação.

Em contextos médicos, a literatura descreve a formulação como um fenômeno de ocorrência rara. Como nos relatam as autoras, para Hak e De Boer ${ }^{2}$ isso reflete a assimetria construída na relação médico-paciente. Em consultas psicoterapêuticas, por outro lado, o uso de formulações é observado com frequência, o que as caracteriza como interações mais colaborativas. Entretanto, os dados analisados por Ostermann e Souza revelam uma frequência considerável de uso de formulações, o que aponta para características mais colaborativas e, por consequência, mais humanizadas nos atendimentos estudados. As análises demonstram que as formulações são utilizadas tanto pelas pacientes quanto pelos profissionais de saúde. Quando proferida pelas pacientes, a formulação explicita entendimentos sobre sua condição de saúde, riscos e tratamentos envolvidos. Quando realizada pelo profissional de saúde, a formulação esclarece dúvidas expressas pela paciente, responde a atribuições e também traz à baila assuntos não necessariamente relevantes para a consulta ginecológica ou obstétrica, mas que dizem respeito ao bem-estar geral das pacientes. Desse modo, a 
ação de formular diminui a assimetria entre os participantes da consulta, tornando-a mais colaborativa.

A quarta e última parte, em que se apresentam capítulos analíticos, inicia com o artigo de Ana Ostermann e Aline Jaeger, intitulado "Gênero e sexualidade no consultório ginecológico: pressupostos identitários jamais questionados". Nesse trabalho, trata-se dos momentos da anamnese na qual o tópico são as práticas sexuais das pacientes. As análises buscam dar visibilidade ao "fazer heteronormativo" que, para Judith Butler, ${ }^{3}$ consiste em tomar a heterossexualidade como um princípio organizador e normativo na sociedade e está estreitamente relacionado a conceitos tradicionais de concepção familiar, sexualidade e, sobretudo, à dicotomia biológica homem-mulher

O trabalho reflete sobre práticas dos médicos que naturalizam determinadas identidades da paciente aprioristicamente, não considerando as múltiplas possibilidades identitárias das mulheres. Os dados revelam que o cuidado com as pacientes está focado apenas na reprodução, e não em questões de outra ordem, como prevenção de doenças sexualmente transmissíveis, por exemplo. Isso demonstra que a responsabilidade pela contracepção e pelo planejamento familiar, ainda nos dias de hoje, é totalmente imputada à mulher

Para além dessa problemática, também observa-se nas análises que, ao se priorizar a saúde reprodutiva da mulher em consultas ginecológicas, há o pressuposto (por parte dos médicos) de que todas as pacientes têm relações heterossexuais, sem que jamais seja considerada a possibilidade de identidades afetivo-sexuais de outra ordem. Assim, esse estudo demonstra como a fala-em-interação desvela o pressuposto heteronormativo operante na sociedade.

Encerrando a parte analítica da coletânea Mariléia Sell e Ana Ostermann apresentam o texto intitulado "Tensionando identidades de gênero e de sexualidade na fala-em-interação: o colapso discursivo da masculinidade homogênea", que se debruça sobre interações entre usuários do SUS aspirantes a um procedimento de vasectomia e uma psicóloga. Nessas consultas, os homens buscam seu aval de sanidade mental a fim de proceder com a vasectomia pelo Programa Nacional de Planejamento Familiar ${ }^{4}$

O capítulo tem como objetivo descrever $e$ analisar o modo como a categoria homem constrói aspectos identitários relacionados a gênero e de que maneira os membros das interações analisadas se orientam para essa categoria e descrevem atributos associados a ela. As análises evidenciam, nas falas dos candidatos à vasectomia, uma das características socialmente atribuídas aos homens: ser sexualmente ativo. Essa construção social, para as autoras, coloca o homem na quase obrigatoriedade de ser "sexualmente potente", o que, por conseguinte, lhe garante maior liberdade sexual. Também é discutido que, ao expressar suas dúvidas com relação ao procedimento da vasectomia em si, os homens são cautelosos ao tratar do medo da impotência (recorrente nos dados analisados), visto que, desde a infância, esse não é um sentimento validado como tipicamente masculino.

Através de constante reitificação interacional, construtos identitários tidos como homogêneos são reificados nessas interações. Assim, questões como a "naturalidade" da potência e do desejo sexual masculino, bem como a fragilidade e a fraqueza comumente associadas ao sentir medo, vão revelando que os seres humanos, desde muito cedo, aprendem que há atividades relacionadas às categorias sociais homem e mulher. $O$ trabalho interacional realizado demonstra que a identidade masculina não é apriorística, mas construída como tal nas interações sociais.

No capítulo final, Stela Meneghel e Ana Ostermann nos propõem uma reflexão: "E então, quais as contribuições dos estudos de fala-eminteração para a atenção em saúde?" (p. 153). Nesse momento, as autoras identificam as contribuições da Análise da Conversa para a relação entre médicos e pacientes, sobretudo com relação à busca de uma medicina mais humanizada em atendimentos no contexto da saúde da muIher. A coletânea nos mostra a possibilidade de se fazer pesquisa entre disciplinas e o quão proveitosa essas parcerias podem ser. O livro consiste portanto, em uma leitura valiosa para profissionais e estudantes de diversas áreas interessadas em interação, gênero, sexualidade, poder, identidade e cuidado em saúde.

\section{Notas}

1 Harvey SACKS, 1992.

2 Tony HAK e Fijgje DE BOER, 1996.

3 Judith BUTLER, 1990.

${ }^{4}$ BRASIL, 1996.

Referências

BRASIL, 1996. Lei $n^{\circ} 9.263$, de 12 de janeiro de 1996. Brasília: Senado Federal. Subsecretaria de Informações. Planejamento Familiar. Disponível em: <http://www.planalto.gov.br/ ccivil/LEIS/L9263.htm>. Acesso em $16 \mathrm{fev}$ 2013. 
BUTLER, Judith. Gender Trouble: feminism and the subversion of identity. Nova York: Routledge, 1990.

HAK, Tony; DE BOER, Fijgje. "Formulations in first encounters." Journal of Pragmatics, v. 25, p. 83-99, 1996.
SACKS, Harvey. Lectures on conversation. Oxford: Blackwell, 1992. v. 2.

Tatiane Rosa Carvalho Universidade do Vale do Rio dos Sinos UNISINOS 